\title{
Transportation Problems and Countermeasures of Changsha Suda Logistics Company
}

\author{
Shijun Yuan \\ Hunan Modern Logistics College \\ Changsha, China
}

\begin{abstract}
This paper takes the transportation management of Changsha Suda Logistics Company as the research object. It firstly expounds the important role of transportation in logistics activities, and then analyzes how Suda Logistics Company correctly understands the logistics transportation management service, and further promotes the rapid, healthy and orderly development of the company's logistics transportation. This paper analyzes the present situation of express logistics company's transportation on the basis of theory and practice, and puts forward the general direction and specific measures on high-speed transportation development of Suda Logistics Company.
\end{abstract}

Keywords-Suda Logistics Company; present situation; problems; countermeasures

\section{INTRODUCTION}

Transportation is indispensable for logistics enterprises to purchase products from production enterprises for warehousing or transfer the stored materials to consumers. Transportation plays an important role in logistics and logistics has a close relationship with traffic. The whole process of logistics is always accompanied by the whole process of production, and the realization of the entire logistics process is always inseparable from the transportation system. The rationalization of transportation is an important way to reduce logistics costs. Therefore, a convenient, fast, efficient, timely, accurate, and safe transportation system is the fundamental guarantee for globalization, integration, and informatization of modern logistics.

\section{The DEVELOPMENT STATUS OF SUDA LOGISTICS COMPANY}

\section{A. Company Profile}

Changsha Suda Logistics Limited Company is a Chinese AA-class logistics company. The company is located in the prime connective location of the 319 State Line Road, 107 State Line Road, Beijing-Zhuhai Expressway, and Changsha-Yongan Expressway exits.

The predecessor of the company was a freight company. The company successfully transformed into a professional third-party logistics enterprise through a series of strategic adjustments such as market positioning, resource restructuring and business integration. In the past 15 years, the company has been adhering to the business philosophy of customer satisfaction and service innovation, and the company also provided clients with professional projects such as large urgent transport, large indoor relocation, storage and distribution, freight forwarding and so on. It has obtained long-term trust and support from customers.

\section{B. Transportation Network and Business Scope}

The company is a logistics company with large-size transportation as its main business, and cooperates with many companies such as Cosco Container Lines, Panpan Group, Sunward, Wangtomg Kegong, Swan pump and other companies. The company provides logistics distribution, automobile transportation, warehousing, and inter-city distribution services. It is a comprehensive logistics company which is cross-regional, networking, informatization, intelligent and with supply chain management ability. It committed to transportation in Hunan Province to the following areas: Changsha, Zhuzhou, Hengyang, Shaoyang, Yueyang, Changde, Chenzhou, Yiyang, Yongzhou, Huaihua, Loudi, Jishou, Xiangtan, Zhangjiajie, and large-scale transportation services throughout the country.

Changsha Suda Logistics Company is a professional logistics company with an integrating supply chain. Its business scope covers Changsha Transportation Company, Changsha Large-size Transportation Company, Changsha Large-size Transportation Service, Changsha Transportation, professional transfer back riding, professional transfer back riding, large-scale logistics service enterprises, empty car loading, large-volume emergency transportation, large-sized indoor relocation, logistics outsourcing, Changsha large-size transportation, and warehousing delivery which is a large logistics service enterprises.

\section{ThE TRANSPORTATION BUSINESS PROCESS OF SUDA LOGISTICS COMPANY}

\section{A. Company Transportation Operation Process}

1) The customers place orders to the company: The customer issues the transportation task to Suda Logistics Company. The customer department should deliver the transportation task to the business department according to the quantity, volume and weight of the goods. The customer should inform the company of the goods and the exact 
address of the delivery, the delivery time, and the delivery person and contact number. So that the company can complete the transportation task, if the customer has special requirements for picking up the goods, such as the requirements of the truck type, and the temporary change of the delivery time and so on. The company needs to be notified in time so that the company can adjust in time to effectively complete the transportation task.

2) The business department accepts orders according to customer requirements: The business department of Suda Logistics Company determines the condition of the goods according to the delivery notice of the customer's order, and according to the condition of the goods and the bill of lading, the amount of the truck should be reasonably arranged. It is necessary to pay attention to the condition of the goods, the time of picking up, the place of picking up, the type of pickup truck and the reasonable time of arrival to make the transportation process effective, safe and timely.

3) Transportation process: The first step is that the dispatching center receives the order and releases the delivery notice. The dispatching center allocates the pickers, and the pickers should pay attention to the check of the goods when picking up the goods at the picking site, and pay attention to the check bill of lading with actual quantity and model. If the actual quantity of the goods and the quantity, weight and model of the bill of lading are not in accordance with each other, the pickers should immediately contact the company's business receptionists. The receptionists should confirm with party A and properly deal with the problems.

The second is that the dispatcher arranges the departure time. The dispatchers shall arrange the departure time of the goods reasonably after the goods are brought back to the company, so as to ensure that the goods can safely arrive at the destination, accurately and timely in accordance with the arrival time requirements of party $\mathrm{A}$.

The next step is signing the receipt form and completing the transportation. After the goods arrive at the destination, the receiving party shall promptly sign the recovery form after the goods have been inspected and accepted, and the office staff will bring the receipts back to the company and the transportation operation is completed.

The final step is the goods in transit management. The company needs to track the goods carried in time to ensure the safe, timely, accurate and orderly transportation process. The customers need to inform the company of the in-transit information of the goods in time. However, the tracking of goods by logistics companies is still not perfect and needs to be improved. As a result, the loss of goods and the failure of the customer to pick up the goods on time during the transportation process.

\section{PROBLEMS IN TRANSPORTATION OF SUDA LOGISTICS COMPANY}

\section{A. The Leased Vehicles Are Difficult to Manage}

Suda Logistics Company has integrated more than 1,000 return vehicles of various types across the country, with more than 20 sets of various transportation vehicles and more than 4,000 new vehicle resources for large trucks nationwide. The company is equipped with large sets of cranes, various types of forklifts, and indoor large equipment translation special tools for loading and unloading equipment. It is strive to achieve rapid response to customer needs, and the customer service is fast and safe. If such a huge resource pool can't well-organized and it will cause confusion. This will directly affect the efficiency of the company's work, which will affect its revenue.

\section{B. Large-scale Transportation Operations and Too Many Manual Steps}

When it comes to the vehicle transportation, it requires more than 5 or more employees to build the slopes to transfer the vehicles into large trucks. First, lifting the assembly ramp down with a forklift, then the slope is divided into 8 sections; each section needs more than three employees aligned up into two groups of slope, screwed into two groups of slope. The two sets of slopes are fixed with screws for the vehicles to come down from the truck. The width of the slopes is carefully calculated according to the vehicle wheels. After the vehicles get down from the truck, the staff will turn back the screws. This process requires a lot of staffs; the details are cumbersome and take a long time. It may lead the entire transportation to fall into a slow state from the beginning.

\section{The Transportation Infrastructure Is Backward}

The company is mainly using the manual operation, the technical level of the logistics system is low, the company parking lot is not standardized, and the vehicle layout is unreasonable. The delivery of the vehicle needs to be increased. When there are too many goods, the delivery vehicles can't normally operate and lead to a decline in transport efficiency. The number of forklifts is limited and can't be shipped in time. There are many pallets, but the damage is large. The planning and construction of various logistics infrastructures lacks the necessary coordination. Therefore, the poor compatibility and compatibility of logistics infrastructure leads to weak system functions.

\section{Transportation Business Process Departments Have a Weak Sense of Cooperation}

The business process is not perfect, the transportation opinions have not received feedback, and the quality of transportation services can't be improved. The customer center, business department, and dispatch center have a weak sense of cooperation and lack of communication. 


\section{E. Drivers Have Low Personal Quality and Weak Sense of Responsibility}

Some drivers do some things that violate the company's rules and regulations during working hours during the transportation process, such as drunk driving, speeding, extending rest time, gambling in the car during working hours, unreasonably delay delivery time, and delivering goods without permission during office hours.

\section{A BRIEF ANALYSIS ABOUT THE TRANSPORTATION STRATEGIES OF SUDA LOGISTICS COMPANY}

\section{A. Introducing Advanced Transportation Equipment}

There is not only competitive relationship, but also cooperative relationship among enterprises. It can achieve complementary advantages and realize mutual benefit. The internal staffs of the company were dispatched to large-scale logistics companies to learn the new using methods of logistics tools. It's necessary to introduce various types of advanced large-sized trucks, which should be reasonably placed and regularly maintained. It can enable the company to undertake more business and no longer use manual methods to move large machinery and equipment for lack of means of transport.

\section{B. Simplifying the Transportation Process}

The customer department can make a monthly statistic according to the customer type, transportation destination and consignment type of goods. The business department conducts statistics according to different transportation modes handled by different goods and makes the data table a detailed statistic. The dispatching center will expect the vehicle dispatching situation next month according to the statistical table.

When the vehicle arrives at the destination, the customer transportation feedback form should be filled and ask for better advice from the customer.

\section{Establishing an Online Tracking System}

Setting up a GPS positioning system to ensure both goods and goods is a new strategy. The driver can reach the destination smoothly without using a map or asking a passerby. In case of emergency such as robbery, traffic accident and vehicle breakdown, the vehicle in transit can report to the police in time. When the vehicle leaves the set route, the monitoring route can be set remotely by the monitoring center. The location of the goods is placed on the Internet for customer inquiry, and the customer can prepare the goods in advance to speed up the entire process.

\section{Cultivating the Quality of Drivers and Encouraging Company Staffs to Apply for Driving Licenses}

The quality of the company's internal personnel directly reflects the corporate culture and image of a company. The quality of a company determines the degree of a company attaches importance to its own culture. At the same time, it also enhances the competitiveness of enterprises and improves the service level. With the rapid development of logistics industrialization, industry standardization and professionalization are the imperative tendency of logistics industry.

- The company should encourage the employees to actively participate in the training of relevant industry certificates such as "Assistant Logistician" and "Logistician" professional qualification certificates. The employees will have a deeper understanding of logistics and have a more professional view of the work after the strict training. It can enhance the sense of belonging of employees and encourage them to do their best to make suggestions for the development of the company.

- The company can cooperates with the driving school to train the insiders with a preferential price, so that more employees will become comprehensive quality talents. It's important to enhance the employees' sense of crisis, and constantly improve their personal skills to stand out.

- The company should adjust their management ideas and working methods, and strive to create a fair competition and a standardized and orderly working environment. The company can set an annual appraisal; excellent performance can get the best transportation employee of the year according to the transportation mileage and personal transportation benefit, and give certain cash reward which depends on the actual situation of the company. The company can also enhance the pressure of employees, and each job should be completed on time and in volume.

\section{E. Creating the Company's Webpage and Online Customer Service}

First, the company can display the company's corporate culture, employee collective activities, fleet, business department, corresponding road and rail consignment goods and large-sized transportation moving on the company's website.

Second, the company's business road map, site, distribution center, and working hours can be placed on the company's website. It allows customers to choose by them, which makes it easier for the salesperson introduce the detailed list of the line charges and avoid unnecessary disputes.

Third, the company can set up a customer satisfaction survey. Customers who accept business in the company can register an account and $\log$ in to evaluate, score, and give some suggest improvements. In this way, every customer can browse the company's website and understand the company's credit level, work efficiency and service attitude.

Forth, the company can provide manual online customer service, so that customers can more easily understand more business. 


\section{CONCLUSION}

Transportation is an important part of logistics activities as well as the core link of logistics. It's important to accelerate the development degree of transportation speed, efficiency and informatization of Suda Logistics Company. It is of great and far-reaching significance to the allocation of resources, adjustment of economic structure, improvement of investment environment, enhancement of economic strength and enterprise competitiveness, improvement of economic operation quality and efficiency, realization of sustainable development strategy, and fundamental transformation of economic system and economic growth mode.

\section{REFERENCES}

[1] Xiong Jiling, Lei Ting. Analysis of the Motivation and Strategy of SME Logistics Outsourcing [J]. China Market, 2008. (in Chinese)

[2] Zhang Li, Li Xuesong. Modern logistics transportation management [D]. Beijing: China Water Resources and Hydropower Press, 2005. (in Chinese)

[3] Dong Yuan. Discussion on measures to strengthen internal control management of road transport enterprises [J]. Enterprise Reform and Management. 2017(22). (in Chinese) 